\title{
DISPROPORTIONATE ENLARGEMENT OF THE PULMONARY AUTOGRAFT IN THE AORTIC POSITION IN THE GROWING PIG
}

Paul H. Schoof, MD

Mark G. Hazekamp, MD, $\mathrm{PhD}^{\mathrm{a}}$

Gijs K. van Wermeskerken, MD $^{\mathrm{a}}$

Emile de Heer, $\mathrm{PhD}^{\mathrm{b}}$

Jan A. Bruijn, MD, $\mathrm{PhD}^{\mathrm{b}}$

Adriana C. Gittenberger-de Groot, $\mathrm{MD}, \mathrm{PhD}^{\mathrm{c}}$

Hans A. Huysmans, MD, $\mathrm{PhD}^{\mathrm{a}}$
Purpose: This study was aimed to demonstrate growth in the pulmonary autograft after transplantation to the aortic position. Methods and materials: In 20 piglets (weight $25.4 \pm 3.5 \mathrm{~kg}$ ) (mean \pm standard deviation) a Ross operation was performed and in five piglets (weight $9.3 \pm 0.7 \mathrm{~kg}$ ) (mean \pm standard deviation) the ascending aorta was replaced with a valveless pulmonary autograft. Animals were allowed to grow as much as possible. Postmortem explanted autografts were studied by direct measurements of the valve cusps in the Ross group and of the wall segments in the valveless autograft group. Measurements of the first group were compared with the values of a separate control group, and values of the second group were compared with values of samples taken at operation. Results: In the Ross group, cuspal weight, height, and width increased significantly by comparison with body weight $(p \leq \mathbf{0 . 0 0 3})$. The rate of increase did not differ significantly from that of the control group with a native pulmonary valve. However, there was a rapid adaptation of the autograft valves resulting in a significantly higher mean cuspal weight, height, and width. In the valveless autograft group, wall circumference, thickness, and height increased significantly $(p \leq \mathbf{0 . 0 0 1})$. The circumference increased significantly more than that of the native pulmonary wall. Compared with the native aortic wall, the pulmonary autograft media showed retained pulmonary architecture on microscopic study. Conclusion: These data suggest that the dimensional increase of the pulmonary autograft in the aortic position in the growing pig is determined by growth and dilatation, that the valve mass increases more than that of the native pulmonary valve, and that the characteristic pulmonary microscopic architecture is retained. ( $J$ Thorac Cardiovasc Surg 1998;115:1264-72)
Duln ulmonary autograft replacement of the aortic valve is applied more frequently and in increasingly younger children on the assumption that the autograft can grow along with the child. ${ }^{1-6}$ Although convincing clinical studies have appeared ${ }^{7,8}$ and valuable experimental contributions have been

From the Departments of Cardiothoracic Surgery, ${ }^{\mathrm{a}}$ Pathology, ${ }^{\mathrm{b}}$ and Anatomy, ${ }^{\mathrm{c}}$ University Hospital Leiden, Leiden, The Netherlands.

Medtronic, Inc., Minneapolis, Minn., is gratefully acknowledged for financial support of this study.

Received for publication June 13, 1997; revisions requested August 29, 1997; revisions received Oct. 14, 1997; accepted for publication Jan. 30, 1998.

Address for reprints: P. H. Schoof, MD, Department of Cardiothoracic Surgery, D6-50, University Hospital Leiden, P.O. Box 9600, 2300 RC Leiden, The Netherlands.

Copyright (C) 1998 by Mosby, Inc.

$0022-5223 / 98 \$ 5.00+0 \quad \mathbf{1 2 / 1 / 8 9 2 9 1}$ made about growth of reimplanted free vascular grafts $^{9,10}$ or pulmonary autografts, ${ }^{11,12}$ there is still uncertainty whether the observed autograft enlargement indicates real growth. ${ }^{3}$ In addition, there is an incidence of reoperation for valve dysfunction caused by progressive aortic insufficiency after the Ross operation which, in some, was attributed to anulus and sinotubular dilatation. ${ }^{13}$ These findings indicate the need for more knowledge about growth and adaptation of the pulmonary autograft in the aortic position. We designed a study primarily intended to find convincing evidence of pulmonary autograft growth. We studied a series of pulmonary autograft roots transplanted to the aortic position in growing pigs and compared them with normal pulmonary roots at different ages. The pig is a particularly suitable animal for this study. It can grow to more than $200 \mathrm{~kg}$ of body weight within 1 year, and during this period there is a linear relationship 

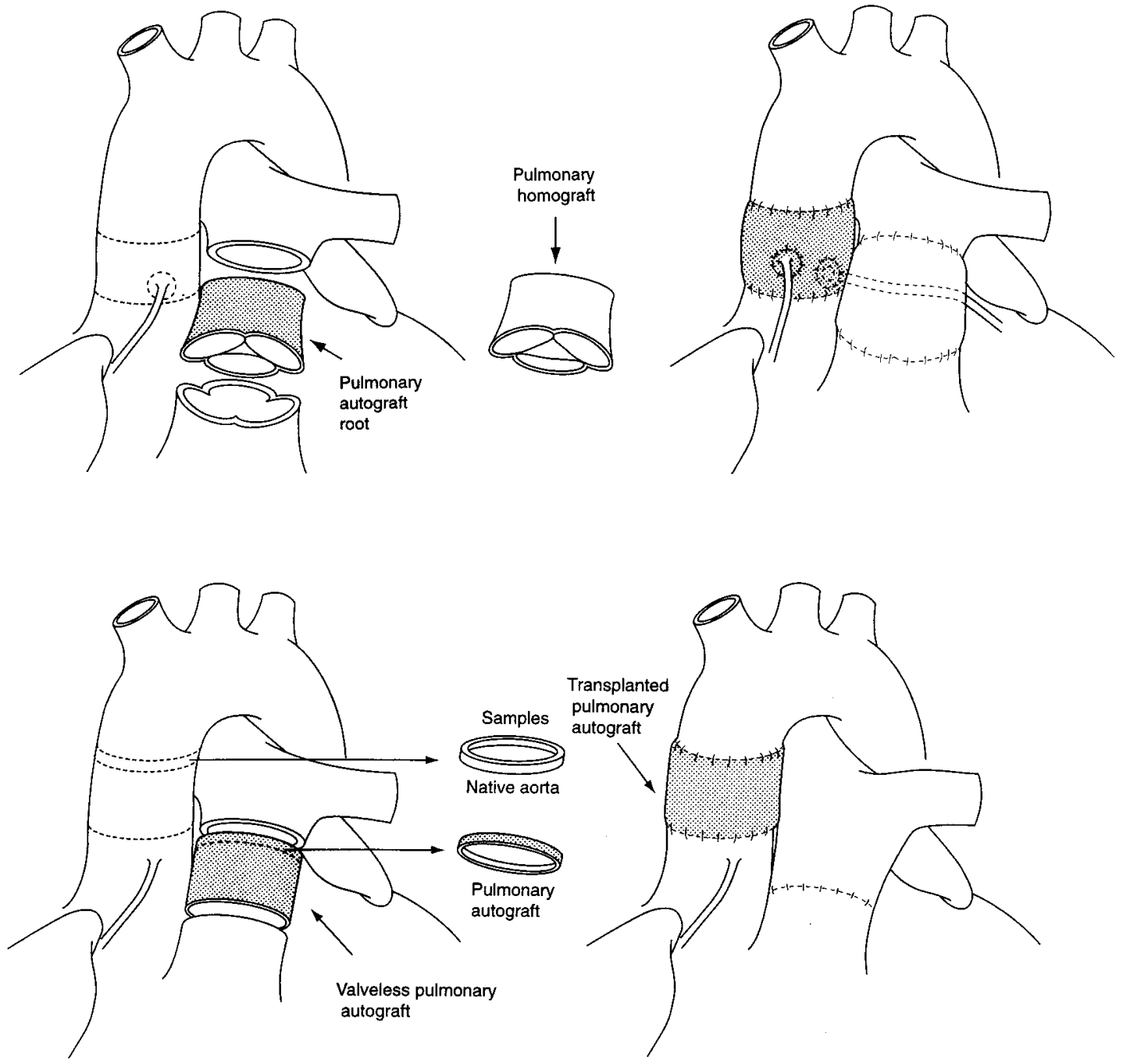

Fig. 1. Sketch showing pulmonary autograft replacement of the aortic root and orthotopic implantation of a pulmonary homograft as performed in group 1 piglets (top) and ascending aortic replacement with a valveless pulmonary autograft as performed in group 2 piglets (bottom).

between age and weight in the studied species. ${ }^{14,15}$ Furthermore, the pig has a cardiac anatomy comparable with that of human beings and is familiar to us from former valve studies. ${ }^{16}$

\section{Methods}

Dutch Landrace piglets of either sex $(n=25)$ were operated on and divided into two groups to enable selective study of the pulmonary autograft valve and wall. In group 1, a complete Ross operation was performed $(n=20$, weight $25.4 \pm 3.5 \mathrm{~kg}$ ) (mean \pm standard deviation [SD]). In group 2, the piglet's ascending aorta was replaced with its valveless main pulmonary artery, with direct reconstruction of the pulmonary artery continuity after sample sections had been taken from the aorta and pulmonary autograft $(n=5$, weight $9.3 \pm 0.7 \mathrm{~kg})$ (mean \pm SD) (Fig. 1). Two animals of group 1 were operated on for a pilot study to assess the feasibility of the present study and were not studied according to the protocol. In view of the anticipated perioperative and postoperative mortality, the number of animals in group 1 was larger than in group 2 . Weight in group 1 was higher to restrict the use of expensive pediatric oxygenators. After the operation, all animals were allowed to grow as much as possible.

Operations. All animals were fasted overnight. After premedication (atropine, ketamine) and being shaved and weighed, they were positioned on the operating table and intubated endotracheally. Intravenous access was obtained by cannulation of an auricular vein, and anesthesia was maintained both intravenously (pancuronium) and 


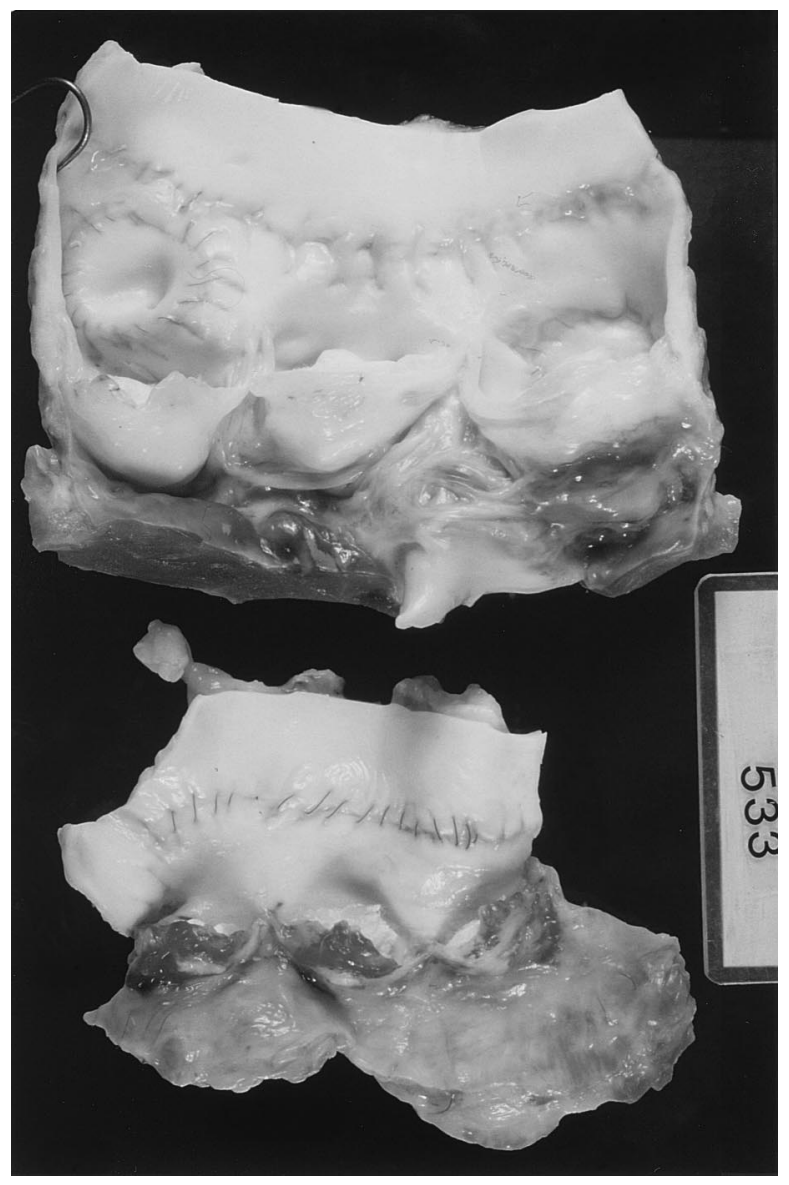

Fig. 2. Autopsy specimens of homograft (bottom) and autograft (top) of a $160 \mathrm{~kg}$ pig showing size difference after growth.

endotracheally (isoflurane, oxygen/nitric oxide). The right jugular vein and carotid artery were cannulated for pressure and blood gas monitoring and for intravenous drug administration. Antibiotic prophylaxis (penicillin, gentamicin) was administered to the prime volume of the heart-lung machine and continued intramuscularly for 5 days after the operation. For each operation, an unmatched donor pig of $40 \mathrm{~kg}$ mean weight was put to death for blood donation. In case a Ross operation was planned, the pulmonary root was sterilely harvested from the donor pig and briefly kept in Ringer's solution for right ventricular outflow tract reconstruction. In group 1 piglets, a median sternotomy was done and the pericardium was opened. Heparin $(2 \mathrm{mg} / \mathrm{kg})$ was administered and the ascending aorta was cannulated as high as possible. After venous cannulation with a right-angled cannula through the auricle, cardiopulmonary bypass with moderate hypothermia was initiated. Apical left ventricular drainage was applied if necessary. The heart was topically cooled and St. Thomas' Hospital crystalloid cardioplegic solution administered in the ascending aorta after crossclamping. The aorta was transected, leaving a $2 \mathrm{~mm}$ cuff in the clamp. Both coronary arteries were excised with a generous button of aortic tissue. Subsequently, valve and wall remnants were excised and the pulmonary root was harvested, with particular attention to the left anterior descending coronary artery and its branches as in the human heart. The pulmonary autograft was subsequently sutured in the anulus of the aortic valve with a running 5-0 Prolene suture (Ethicon, Inc., Somerville, N.J.) in a continuous fashion, with one commissure being located halfway between the two coronary buttons. With the use of 6-0 Prolene suture, the left coronary button was reimplanted in a punch-hole into the corresponding sinus and right coronary reimplantation was performed close to and sometimes within the distal suture line to prevent coronary artery kinking. During rewarming, pulmonary artery continuity was reestablished with the pulmonary homograft procured from the donor pig, with 6-0 Prolene suture for the distal anastomosis and 5-0 Prolene suture for the proximal anastomosis. In four pigs, a $23 \mathrm{~mm}$ Freestyle stentless aortic bioprosthesis (Medtronic, Inc., Minneapolis, Minn.) was used for reconstruction of the right ventricular outflow tract.

In group 2 piglets, normothermic cardiopulmonary bypass was initiated after similar aortic and atrial cannulation. After aortic clamping and cold cardioplegic arrest, the aorta was transected and a segment of aortic wall was excised and fixed in $3.6 \%$ formaldehyde to serve as a reference sample. Subsequently, the main pulmonary artery was excised from the top commissural level up to the bifurcation. A sample was taken from the valveless autograft and fixed in $3.6 \%$ formaldehyde to serve as a reference sample. Aortic continuity was reestablished with the remaining autograft after the height of the segment was measured with a ruler. Anastomoses were made with 6-0 Prolene suture in a continuous fashion. The right ventricular outflow tract was reconstructed by mobilization of the pulmonary artery branches and direct anastomosis with 6-0 Prolene suture.

At normothermia the extracorporeal circulation was discontinued, the heart decannulated, and the chest closed, with drains being left in the pericardium and beneath the sternum.

Postoperative course. All animals were extubated primarily or within a few hours after the operation and transported to a temperature- and oxygen-regulated intensive care unit, where appropriate guidelines for postoperative care were followed. All animals stayed in the laboratory for 2 to 3 weeks before they were returned to the farm, where they were fed unrestrictedly.

Throughout the study period, all animals received humane care in compliance with the "Dutch Animal Welfare Act." The experimental protocol was reviewed and approved by the University of Leiden Committee on the Care and Use of Laboratory Animals.

Euthanasia. Animals not dying of a natural cause were put to death when they became seriously ill, symptoms of heart failure developed, or when they had reached considerable weight (more than $100 \mathrm{~kg}$ ) in group 1 .

In group 2 all animals were put to death at 10 months of age with the use of metomidate hydrochloride, azaperone, pancuronium, and potassium chloride. 


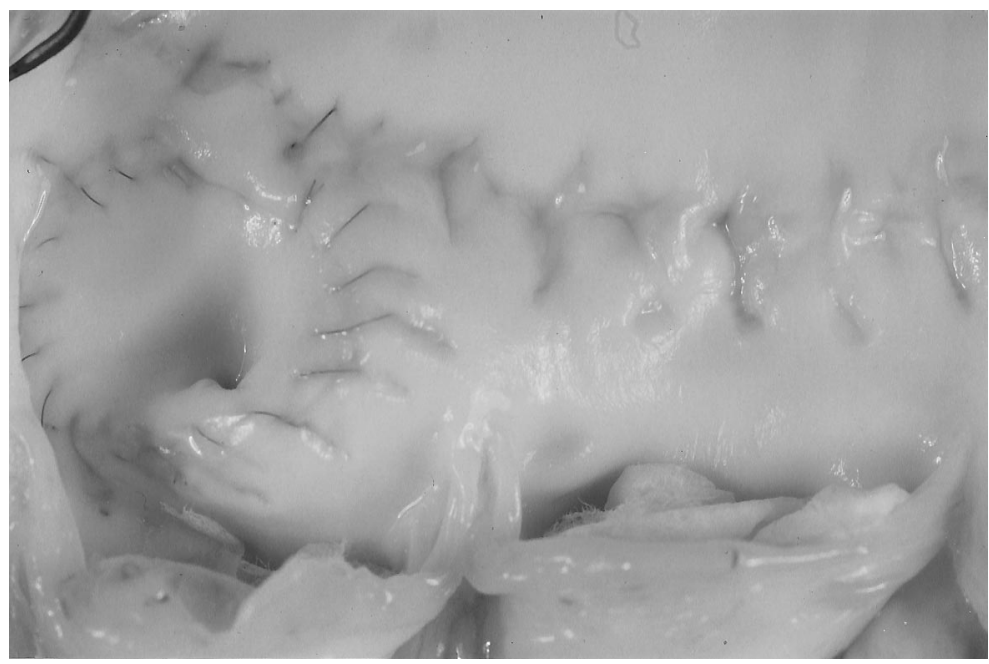

Fig. 3. Detail of autograft specimen shown in Fig. 5, showing "growth tracks" left by the sutures.

Autopsy. In all animals that died of a natural cause, an extensive autopsy was performed to establish a cause of death. In all other animals a limited thoracotomy was made to excise the heart and proximal great vessels. After transection and inspection of the ventricles, the autograft was dissected free together with the homograft or bioprosthesis in group 1 animals. The coronary remnants were sutured and autograft valve sufficiency was checked by filling the root with Ringer's solution. Other means of assessment of valvular function were considered, such as echocardiography and auscultation, but could not be carried out in the often huge and uncooperative animals. Macroscopic photographs were made after longitudinal transection between the left and right coronary cusps after fixation in $3.6 \%$ formaldehyde (Fig. 2). In group 2, transverse sample rings were taken from the pulmonary autograft, native aorta, and native main pulmonary artery.

Measurements. All length measurements of autopsy specimens were performed on formaldehyde-fixed tissues with a vernier calliper. In group 1 , total cuspal width was determined by measuring the distance between each of the two commissures and adding the three values together. Cuspal height was measured from the top of the commissures to the lowest point of cuspal insertion. Total cuspal weight was measured on a Sartorius H51 scale (Sartorius AG, Goettingen, West Germany) after each cusp was excised with microscissors and dried in absorbent paper.

In group 2, inner circumference was determined by measuring the length of the opened tissue sample rings. Height of the pulmonary autograft was measured with a vernier calliper on the outside of the specimen after the anastomoses had been cleared. Sample thickness was measured microscopically with a microscopic grid at $10 \times$ magnification; the wall thickness was measured from external elastic lamina to internal luminal surface, precluding measuring faults from adventitial irregularities.
Controls. A separate control group was introduced to create a normal growth curve of the pulmonary valve. The pulmonary root was procured from 20 healthy Dutch Landrace pigs. Ten pigs operated on for another experiment weighed $25.5 \pm 2.8 \mathrm{~kg}$ (mean $\pm \mathrm{SD}$; range 20.0 to $30.7 \mathrm{~kg}$ ), and 10 pigs weighing $86.0 \mathrm{~kg}$ (mean) were slaughtered for consumption. All roots were fixed in $3.6 \%$ formaldehyde and transected. Cuspal width, height, and weight were measured as in group 1 specimens.

Because there is a linear relationship between age and body weight between 20 and $200 \mathrm{~kg}$ in Dutch Landrace piglets, ${ }^{14,15}$ the assumption was made that valve growth is also linearly related to body weight and thus to age in this particular weight range. This linear relationship is also found in human beings above a certain body surface area equaling approximately $10 \mathrm{~kg}$ body weight. ${ }^{17,18}$ Thus the created normal growth curves can be extrapolated and compared with the curves of the study group.

In the valveless autograft group 2, the values of the autopsy specimens were compared with the similarly measured samples taken at operation.

Microscopy. Longitudinal sections of the transition zone between the native aorta and the pulmonary autograft were stained with hematoxylin-eosin and elastin van Gieson stains and were studied with a light microscope. More extensive microscopy was considered beyond the scope of this project and will be the subject of further study.

Statistics. Comparison of means was done with unpaired Student's $t$ tests and correlations were calculated by means of Pearson's product moment correlation coefficients. The relations between body weight and cuspal width, height, and weight of group 1 animals were estimated with linear regression. The slopes of the regression lines between the cuspal weight, height, and width and the body weight of the group 1 animals and the control group animals were compared by means of covariance analysis, 

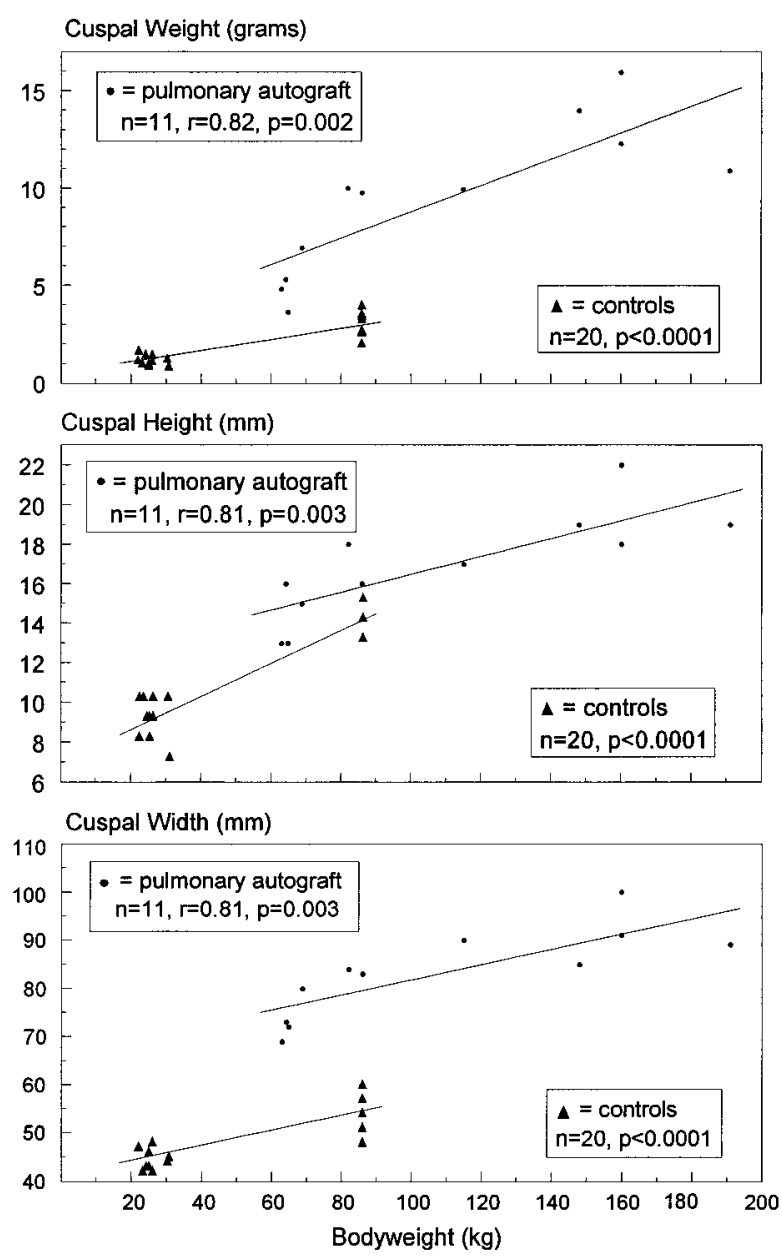

Fig. 4. Graphs showing the relationship between total cuspal weight, cuspal height, and total cuspal width of the pulmonary autograft and the body weight in group 1 animals.

in which we evaluated the interaction tests between body weight and group membership.

\section{Results}

Operative and early mortality ( $\leq 30$ days) occurred in six pigs in the Ross group. Cause of death was myocardial ischemia caused by coronary artery kinking in one, an ill-defined anesthetic problem in one, early tamponade in one, severe bioprosthetic and autograft endocarditis in one, and an unknown cause unrelated to the autograft in two pigs.

Two pigs were put to death after 2 and 12 weeks for the purpose of a pilot study; their autograft was not studied according to the protocol. One autograft was damaged at dissection and could not be reliably measured.

Finally, 11 pigs were the subject of study and their autograft valves were measured. They lived for more than 3 months $(6.6 \pm 2.3$, mean $\pm \mathrm{SD}$, range 3 to 11 ), acquiring a mean weight of $109.3 \pm 48.4 \mathrm{~kg}$ (mean $\pm \mathrm{SD}$, range 63.0 to $191 \mathrm{~kg}$ ). Six pigs died during follow-up: Four died of right ventricular failure caused by outflow tract obstruction or insufficiency (three of them had a stentless bioprosthesis in the right ventricular outflow tract); one died of pneumonia; and one pig died of an unknown cause. Five pigs were put to death at a weight of $143.3 \pm$ $37.4 \mathrm{~kg}$ (mean $\pm \mathrm{SD}$, range 85.5 to $191 \mathrm{~kg}$ ), four being in good health and one showing signs of right ventricular failure.

No operative or early deaths occurred in the valveless autograft group. All animals were in good health when put to death at 10 months of age and at a weight of $179.2 \pm 10.4 \mathrm{~kg}$ (mean $\pm \mathrm{SD}$, range 161 to $186 \mathrm{~kg}$ ).

At autopsy the pulmonary autograft was found to have enlarged in proportion with or slightly more than adjacent native structures. In large animals, a remarkable size discrepancy between right-sided homograft and autograft was observed (Fig. 2). In the transected autograft, all valve cusps showed the transparent, smooth, and shiny appearance of a healthy valve with good pliability and coaptation. Small tracks left by the Prolene stitches could be seen at anastomotic lines where sutures were still visible (Fig. 3). No insufficiency of any autograft was found when the valve was tested with Ringer's solution after coronary closure.

The sum of pulmonary autograft valve cuspal weights was $0.94 \pm 0.37 \mathrm{gm}$ (mean $\pm \mathrm{SD}$, range 0.36 to $1.60 \mathrm{gm})$ and correlated significantly with body weight $(r=0.82, p=0.002)$, as in the control group $(p<0.0001)$. The rate of cuspal weight increase did not differ significantly between autografts and controls $(p=0.33)$, but there was a significantly higher mean cuspal weight in the autograft group ( $p<$ 0.001) (Fig. 4).

Height of the pulmonary autograft cusps was $17 \pm$ $3 \mathrm{~mm}$ (mean $\pm \mathrm{SD}$, range 13 to $22 \mathrm{~mm}$ ). It correlated significantly with body weight in both the autograft group $(r=0.81, p=0.003)$ and the control group $(p<0.0001)$. The rate of cuspal height increase did not differ between the two groups ( $p=$ $0.54)$. Mean cuspal height was significantly greater in the autograft group $(p<0.008)$ (Fig. 4).

The sum of the pulmonary autograft valve cuspal 


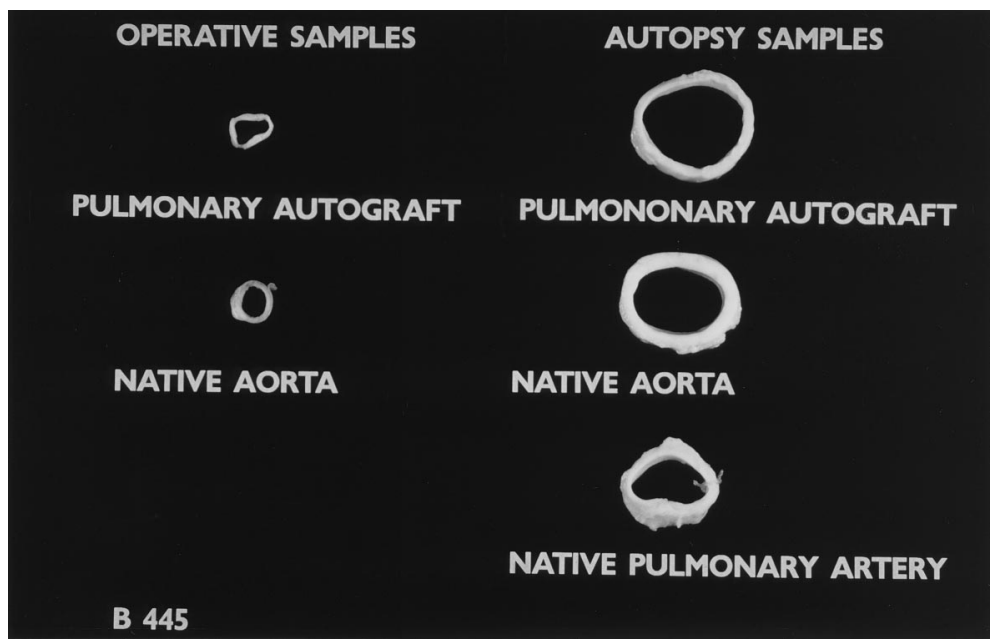

Fig. 5. Operative and autopsy samples of native pulmonary artery, aorta, and pulmonary autograft in one of the group 2 animals showing difference in size before and after growth.

widths was $83 \pm 9 \mathrm{~mm}$ (mean $\pm \mathrm{SD}$, range 69 to 100 $\mathrm{mm}$ ), which correlated significantly with body weight in both the autograft $(r=0.81, p=0.003)$ and the control group $(p<0.0001)$. The rates of cuspal width increase did not differ significantly $(p=0.18)$, but the mean cuspal width was significantly greater in the autograft group $(p \leq 0.001)$ (Fig. 4).

A remarkable size increase could be observed by comparing the operative and autopsy samples in the valveless autograft group (Fig. 5). The inner circumference increased from $38.8 \pm 4.9$ to $88.6 \pm 6.3 \mathrm{~mm}$ in the pulmonary autograft, $38.8 \pm 4.9$ to $66.0 \pm 4.0$ $\mathrm{mm}$ in the native pulmonary artery, and $34.4 \pm 1.6$ to $77.0 \pm 7.2 \mathrm{~mm}$ in the aorta (all mean $\pm \mathrm{SD}$ and $p \leq 0.001$ ). The circumference had increased significantly more in the pulmonary autograft than in the native pulmonary artery $(p=0.002)$ (Fig. 6).

Wall thickness had increased from $1.01 \pm 0.15$ to $2.09 \pm 0.21 \mathrm{~mm}$ in the pulmonary autograft (mean $\pm \mathrm{SD}, p<0.001$ ), from $1.36 \pm 0.24$ to $2.76 \pm$ $0.25 \mathrm{~mm}$ in the aorta (mean $\pm \mathrm{SD}, p<0.001$ ), and from $1.01 \pm 0.15$ to $2.06 \pm 0.51 \mathrm{~mm}($ mean $\pm \mathrm{SD}$, $p=0.007)$ in the native pulmonary artery. The difference in wall thickness between the aorta and pulmonary autograft remained significant $(p<$ 0.001) (Fig. 6). This difference could also be seen in the macroscopic samples (Fig. 5).

Both height and volume of the transplanted segment increased significantly $(5 \pm 0.9$ to $16.2 \pm 3.1$ $\mathrm{mm}[$ mean $\pm \mathrm{SD}$ ], $p=0.001$, and $174.6 \pm 40.2$ to $3014.8 \pm 687.2 \mathrm{~mm}^{3}$ [mean $\pm \mathrm{SD}$ ], $p=0.001$, respectively) (Fig. 6). Microscopic sections of pulmonary autograft to the native aortic wall transition zone, stained with hematoxylin-eosin and elastin van Gieson stains, showed a restorative response that had caused fibrosis with numerous vasa vasorum on the outside and intact endothelium on the inside. On the outside, irregular thickening of the adventitia was seen as a possible result of operative trauma. The architectural differences between the aortic media and the pulmonary media of the autograft were retained, with the thick, densely packed, and well-organized elastic lamellae of the aortic media and the thinner less-organized elastic lamellae of the pulmonary media (Fig. 7).

\section{Discussion}

Growth is the "process of increase in size of an organism as a result of accretion of tissue similar to that originally present." 19 In this study, there is a significant increase in all measured dimensions with a weight increase of the valve cusps (group 1) and a volume increase of the transplanted autograft wall segment (group 2), indicating mass increase. Together with the preserved histologic architecture of both tissue segments shown at microscopy, it can be concluded that true growth had occurred.

In group 1, cuspal weight, height, and width increased significantly with body weight and at a rate that is comparable with growth of the native pulmonary valve. However, there was a rapid adaptation in the autograft valves resulting in a significantly higher 

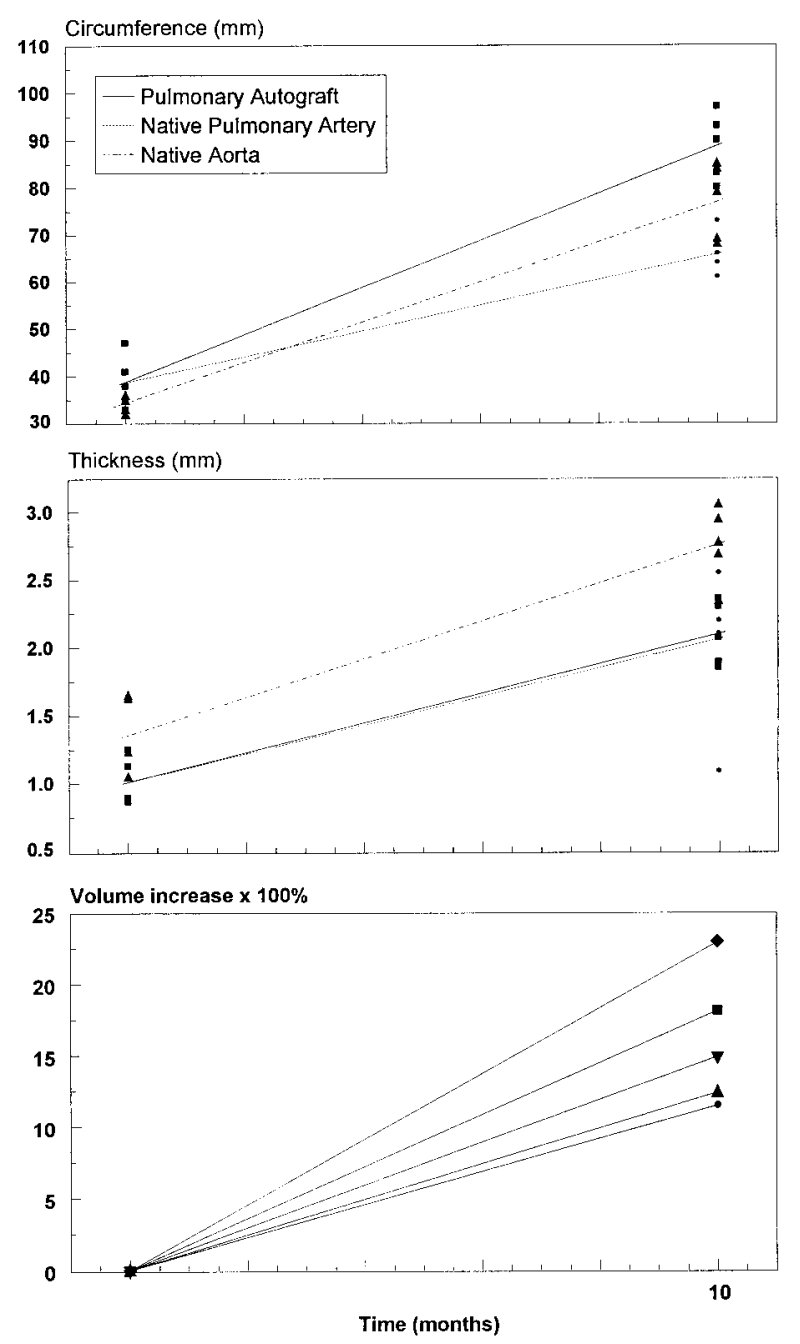

Fig. 6. Graphs showing the increase in circumference (top) and thickness (middle) of the pulmonary autograft (filled squares), native pulmonary artery (filled circles), and native aorta (filled triangles) and the volumetric increase (bottom) of the transplanted pulmonary autograft segment in each and all group 2 animals. Because group 2 animals were studied systematically at 10 months alone, the linear regression lines shown are intended for visual reference and do not imply that the increases across time necessarily follow a linear pattern.

mean cuspal weight, height, and width. Weight increase of the cusps may be a sign of remodeling, for example, caused by increased collagen content as a response to increased pressure load. The higher mean cuspal height and width, however, indicate that the dimensional increase of the valve is determined not only by growth alone but also by dilata- tion. It is additionally reflected in the significant difference in circumference between autograft and native pulmonary wall after growth (Fig. 6). We think this dilatation occurs early, causing the step-up of the autograft curve that can be observed in the cuspal width curve (Fig. 4). Considering the in vitro experiments of Sievers and associates, ${ }^{20}$ demonstrating a steep diameter increase at the commissural level of the loaded porcine pulmonary artery up to a static pressure of $50 \mathrm{~mm} \mathrm{Hg}$ and our own clinical impression that the autograft exhibits unvariably a certain dilatation after aortic unclamping, we think that the most important dilatation of the pulmonary root occurs intraoperatively at unclamping. It probably is not equally distributed throughout the autograft but rather is more pronounced in those parts of the root that are not fixed in circumferential anastomoses. This may also cause some parts to dilate later than others and might explain the different clinical echocardiographic findings of several authors. $8,20,21$ Our experimental findings are in agreement with the clinical findings of Elkins and coworkers, ${ }^{8}$ who demonstrated that growth of the pulmonary autograft root replacement is associated with dilatation.

Another sign of growth was the finding of small tracks left by the Prolene sutures and visible at the anastomotic sites of the luminal surface of the macroscopic specimen (Fig. 3). The continuous suture may represent a spiral whose coil becomes smaller with increasing diameter of the growing vessel. It is pulled in the direction of the anastomosis, leaving small scars in the growing vessel wall, perpendicular to the suture line.

Now that growth and dilatation have been found to be responsible for the dimensional increase of the pulmonary autograft in the aortic position, the question of adaptation should be addressed. Like the semilunar valve cusps, with their intricate, stressminimizing shearing properties, the vessel wall is also an active integrated organ that is composed of endothelial, smooth muscle, and fibroblast cells coupled to each other in a complex autocrine-paracrine set of interactions. ${ }^{22} \mathrm{~A}$ sudden and persisting increase in wall stress and shearing force exerted on the autograft and the sudden passage of oxygen-rich blood constitute strong stimuli that should lead to a remodeling response in both wall and valvular tissue. Elucidating the expression of this remodeling might enable the physician to predict the fate of the pulmonary autograft. As for some early vascular changes in systemic hypertension, future degenera- 

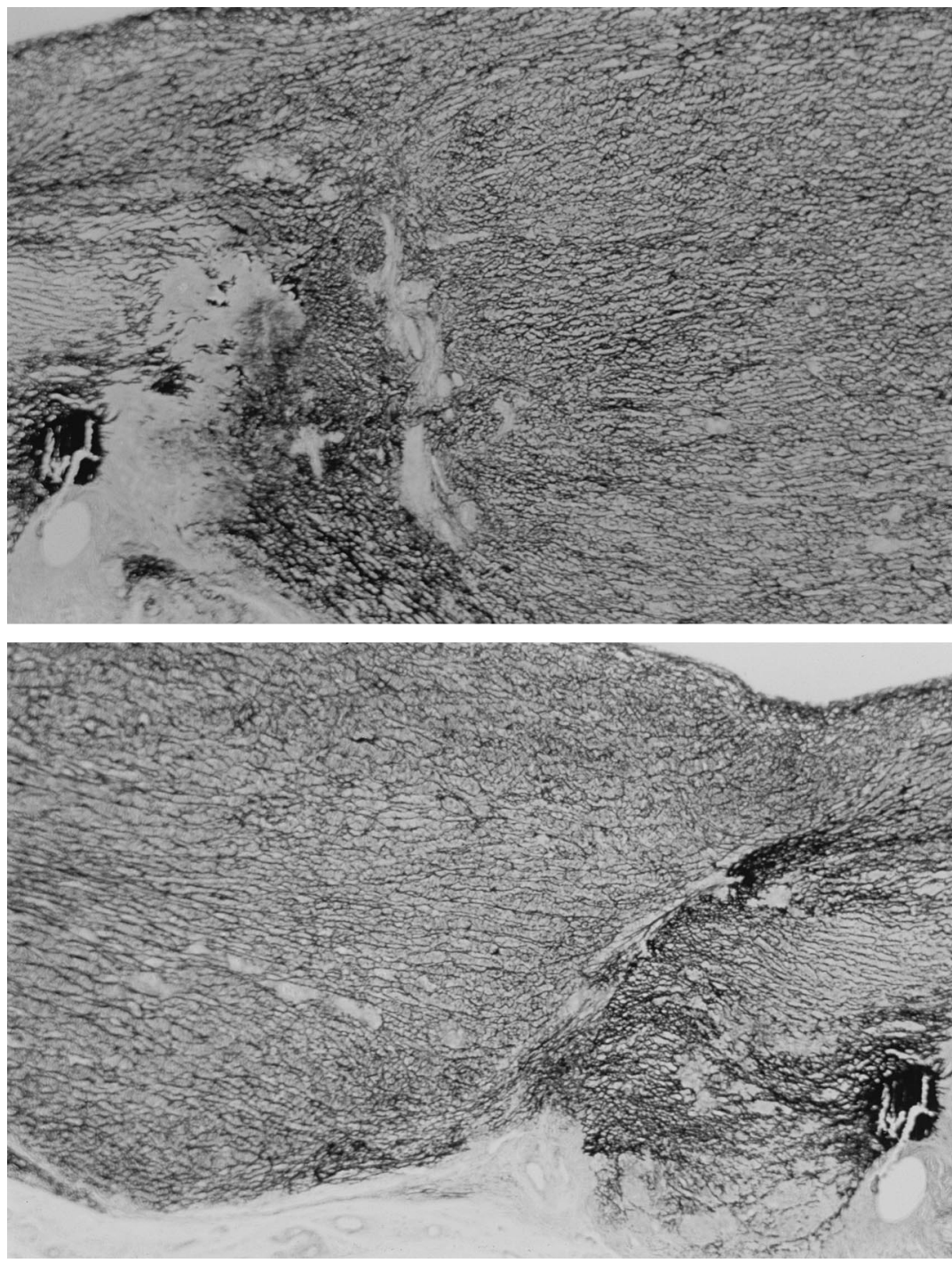

Fig. 7. Elastin van Gieson-stained microscopic section $(10 \times$ magnification $)$ of the transition zone between the aorta (top) and pulmonary autograft (bottom). The aortic media shows densely packed, well-organized elastic fibrils, whereas the pulmonary autograft media still shows the thinner, loosely arranged media, characteristically seen in the pulmonary artery wall.

tion can be predicted. ${ }^{22}$ The pulmonary autograft wall showed retained pulmonary characteristics at both microscopic and macroscopic inspection. These findings demonstrate that remodeling is a subtle process that does not lead to conversion of the pulmonary wall to an aortic wall but probably remains restricted to the differentiation of a few cell types with the potential to respond to altered mechanical load.

In conclusion, the dimensional increase of the pulmonary autograft in the aortic position in the growing pig is caused by growth and dilatation. The autograft valve acquires more weight than does the native growing pulmonary valve. During growth, the histologic differences between pulmonary autograft and native aortic media are retained.

We gratefully acknowledge the following individuals: Everyone from the animal laboratory; K. H. vd Nat, head; F. Boer, anaesthesiologist; C. van Seggelen, farmer; J. 
Baelde, pathology laboratory; L. Pronk, anatomy laboratory; and assistants from the de Jager slaughterhouse. A. H. Zwinderman, PhD, and A. P. Kappetein, MD, PhD, are acknowledged for statistical help.

\section{REFERENCES}

1. Sudow G, Solymar L, Berggren H, Eriksson B, Holmgren D, Gilljam T. Aortic valve replacement with a pulmonary autograft in infants with critical aortic stenosis. J Thorac Cardiovasc Surg 1996;112:433-6.

2. Calhoon JH, Bolton JWR. Ross/Konno procedure for critical aortic stenosis in infancy. Ann Thorac Surg 1995;60:S597-9.

3. Starnes VA, Luciani GB, Wells WJ, Allen RB, Lewis AB. Aortic root replacement with the pulmonary autograft in children with complex left heart obstruction. Ann Thorac Surg 1996;62:442-9.

4. Reddy VM, Rajasinghe HA, Teitel DF, Haas GS, Hanley FL. Aortoventriculoplasty with the pulmonary autograft: the "RossKonno" procedure. J Thorac Cardiovasc Surg 1996;111:158-67.

5. Quaegebeur JM, Solowiejczyk D, Hsu DT, Bourlon F, Hess J, Gersony W. Does the Ross operation provide a definitive solution for children with complex left ventricular outflow tract obstruction? [abstract]. Presented at the Seventy-fourth Annual Meeting of the American Association for Thoracic Surgery, New York [NY]. April 23-26, 1994.

6. Van Son JAM, Falk V, Mohr FW. Ross-Konno operation with resection of endocardial fibroelastosis for critical aortic stenosis with borderline-sized left ventricle in neonates. Ann Thorac Surg 1997;63:112-6.

7. Santangelo K, Elkins RC, Stelzer P, et al. Normal left ventricular function following pulmonary autograft replacement of the aortic valve in children. J Card Surg 1991; 6(suppl):633-7.

8. Elkins RC, Knott-Craig CJ, Ward KE, McCue C, Lane MM. Pulmonary autograft in children: realized growth potential. Ann Thorac Surg 1994;57:1387-94.

9. Shumacher HB, Freeman LW, Hutchings LM, Radigan L. Further observations on the growth of anastomoses and free vascular transplants in growing animals. Angiology 1951;2: 263-9.
10. Kreitmann B, Riberi A, Jimeno MT, Metras D. Experimental basis for autograft growth and viability. J Heart Valve Dis 1995;4:379-83.

11. Murata H. A study of autologous pulmonary valve replantation. J Jpn Assoc Thorac Surg (Nippon Geka Gakkai Zasshi) in Japanese. 1984;32:144-8.

12. Walls JT, McDaniel WC, Pope ER, et al. Documented growth of autogenous pulmonary valve translocated to the aortic valve position. J Thorac Cardiovasc Surg 1994;107: 1530-1.

13. Elkins RC, Knott-Craig CJ, Howell CE. Pulmonary autografts in patients with aortic annulus dysplasia. Ann Thorac Surg 1996;61:1141-5.

14. Kanis E, Koops WJ. Daily gain, food intake and food efficiency in pigs during the growing period. Anim Prod 1990;50:353-64.

15. Walstra P. Communications, Agricultural University Wageningen 80-4. 1980.

16. Hazekamp MG, Goffin YA, Huysmans HA. The value of the stentless biovalve prosthesis: an experimental study. Eur J Cardiothorac Surg 1993;7:514-9.

17. Rowlatt JF, Rimoldi JH, Lev M. The quantitative anatomy of the normal child's heart. Pediatr Clin North Am 1963; 10:499.

18. Sievers HH, Onnash DG, Lange PE, Bernhard A, Heintzen PH. Dimensions of the great arteries, semilunar valve roots and right ventricular outflow tract during growth: normative angiocardiographic data. Pediatr Cardiol 1983;4:189.

19. Dorland's Illustrated Medical Dictionary. 28th ed. Philadelphia. WB Saunders Company; 1994.

20. Sievers HH, Leyh R, Loose R, Guha M, Petry A, Bernhard A. Time course of dimension and function of the autologous pulmonary root in the aortic position. $\mathrm{J}$ Thorac Cardiovasc Surg 1993;105:775-80.

21. Kouchoukos NT, Davila-Roman VG, Spray TL, Murphy SF, Perrillo JB. Replacement of the aortic root with a pulmonary autograft for aortic valve disease in children and young adults. N Engl J Med 1994;330:1-6.

22. Gibbons GH, Dzau VJ. The emerging concept of vascular remodeling. N Engl J Med 1994;330:1431-8.

\section{Availability of Journal back issues}

As a service to our subscribers, copies of back issues of The Journal of Thoracic and Cardiovascular Surgery for the preceding 5 years are maintained and are available for purchase from Mosby at a cost of $\$ 16.00$ per issue until inventory is depleted. The following quantity discounts are available: $25 \%$ off on quantities of 12 to 23, and one third off on quantities of 24 or more. Please write to Mosby, Inc., Subscription Services, 11830 Westline Industrial Drive, St. Louis MO 63146-3318, or call 800-453-4351 or 314-453-4351 for information on availability of particular issues. If unavailable from the publisher, photocopies of complete issues may be purchased from UMI, 300 N. Zeeb Rd., Ann Arbor, MI 48106, 313-761-4700. 